Indonesian Journal of Electronics and Instrumentation Systems (IJEIS)

Vol.8, No.1, April 2018, pp. 49 60

ISSN (print): 2088-3714, ISSN (online): 2460-7681

DOI: $10.22146 /$ ijeis.25512

\title{
Klasifikasi Kakao Berbasis e-nose dengan Metode Neuro Fuzzy
}

\author{
Ikhsan Nur Rahmani.* ${ }^{1}$, Danang Lelono ${ }^{2}$, Kuwat Triyana ${ }^{3}$ \\ ${ }^{1}$ Prodi Elektronika dan Instrumentasi, DIKE, FMIPA, UGM, Yogyakarta, Indonesia \\ ${ }^{2}$ Departemen Ilmu Komputer dan Elektronika, FMIPA UGM, Yogyakarta, Indonesia \\ ${ }^{3}$ Departemen Fisika, FMIPA UGM, Yogyakarta, Indonesia \\ e-mail: *21 ikhsaninr@gmail.com, ${ }^{2}$ dananglelono@gmail.com, ${ }^{3}$ triyana@ ugm.ac.id
}

\begin{abstract}
Abstrak
Selama ini untuk mengidentifikasi kualitas mutu kakao berdasarkan warna dan aroma dengan melibatkan human tester. Namun tester tahu ini masih memiliki kelemahan seperti bersifat subyektif. Disamping itu, metode analitik kimia standar membutuhkan biaya yang besar dan tenaga ahli dalam menganalisanya. Pada dasarnya aroma kakao sangat ditentukan senyawa volatile seperti aldehid dan alkohol. Electronic nose berbasis larik sensor gas tak terseleksi (unselected) memiliki kemampuan untuk menganalisa sampel dengan komposisi yang kompleks sehingga dapat diketahui karakteristik dan analisa kualitatif dari sampel tersebut. Stimulus aroma dirubah oleh electronic nose menjadi fingerprint data yang kemudian digunakan untuk proses ekstraksi ciri menggunakan metode differensial. Hasil dari ekstraksi ciri digunakan untuk proses pelatihan neuro fuzzy untuk mendapatkan parameter optimal. Parameter yang telah dioptimasi ini kemudian diujikan pada sampel kakao. Berdasarkan hasil pengujian, neuro fuzzy dapat mengidentifikasi sampel dengan tingkat akurasi 95,21\% sehingga klasifikasi mutu kakao dengan electronic nose menggunakan analisis neuro fuzzy telah berhasil dilakukan.
\end{abstract}

Kata kunci-Hidung elektronik, fuzzy, jst, kakao

\begin{abstract}
During this time to clasify quality of cacao based on color and aroma involving human taster. But this cacao tester still has weaknesses such as subjective. Besides that, the standard chemical analytical methods requires a high cost and need expertise to analyzing it. Basically aroma of cacao is determined by volatile compounds such aldehid and alcohol. Electronic nose based on unselected gas sensor array has the ability to analyze samples with complex compositions that can be known characteristics and qualitative analysis of the samples. Stimulus aroma is transformed by electronic nose into fingerprint data then it is used by feature extraction process using the differential method. The results of feature extraction is used to process the neuro fuzzy training to obtain optimal parameters. The parameters have been optimized is then tested on cacao. Based on test results, neuro fuzzy can clasify samples with $95,21 \%$ accuracy rate so that the clasification of cacao quality with electronic nose using neuro fuzzy has been successfully carried out.
\end{abstract}

Keyword-Artificial neural network, fuzzy, electronic nose, cacao.

Received May 31 ${ }^{\text {th }}, 2017 ;$ Revised March 29 ${ }^{\text {th }}, 2018 ;$ Accepted April 30 ${ }^{\text {th }}, 2018$ 


\section{PENDAHULUAN}

Kakao (Theobroma cacao L) dikenal juga dengan nama cokelat. Salah satu jenis buah kakao adalah kakao lindak (Amelonado/Forastero) atau dikenal dengan nama kakao curah / bulk cacao. Secara fisik, ciri dari jenis kakao lindak adalah hasil panen tinggi, tahan hama dan penyakit, cita rasa terbaik, kulit halus, tipis, dan keras [1]. Kakao lindak merupakan kakao yang banyak diproduksi oleh petani Indonesia [2]. Indonesia sendiri merupakan negara penghasil kakao terbesar nomor tiga di dunia setelah Pantai Gading dan Ghana [3]. Adapun untuk mendapatkan perhatian dari konsumen dunia dan agar kakao Indonesia senantiasa disukai maka mempertahankan dan meningkatkan mutu kakao lindak ini sangat diperlukan.

Berdasarkan mutunya, kakao lindak digolongkan dalam 3 jenis, yaitu mutu I, mutu II, dan mutu III. Menurut ukuran berat bijinya, dinyatakan jumlah biji per $100 \mathrm{~g}$ sampel, biji kakao digolongkan menjadi 5 golongan, yaitu AA, A, B,C, dan S. Selama ini penentuan mutu kakao menggunakan tester manusia yang sudah berpengalaman atau dilatih terlebih dahulu, disamping itu tester ini mempunyai kekuatan dengan suatu badan hukum [4]. Hal lain yang erat kaitannya dengan mutu kakao tersebut adalah syarat mutu kakao yang terdiri dari syarat umum mencakup uji serangga hidup, kadar air, biji berbau asap atau bau asing, dan kadar benda asing; dan syarat khusus mencakup kadar biji berjamur, kadar biji slaty, kadar biji berserangga, kadar kotoran dan kadar biji berkecambah. Kakao lindak ini sesuai SNI 19-1428-1998, dimana menurut aturan tersebut, cara uji meliputi penentuan adanya serangga hidup dan benda asing, penentuan kadar air, penentuan adanya biji berbau asap abnormal dan berbau asing lainnya, penentuan kadar kotoran, penentuan kadar biji pecah, penentuan jumlah biji kako per $100 \mathrm{~g}$, penentuan kadar biji cacat pada kakao (biji berjamur, biji slaty, biji berserangga, biji berkecambah) kemudian biji kakao dinyatakan lulus uji apabila memenuhi syarat mutu yang ditetapkan.

Salah satu poin dalam penentuan mutu kakao dalam syarat umum di atas adalah aroma kakao harus bebas dari bau asap dan atau bau abnormal dan atau bau asing lainnya sedangkan penentuan syarat mutu ini dilakukan oleh petugas yang sudah terlatih dengan menggunakan penciuman sebagai instrumennya. Walaupun metode ini lebih realitis namun pada dasarnya memiliki kelemahan yaitu bersifat subjektif dan sulit dilakukan standardisasi [5]. Metode lain yang bisa digunakan adalah dengan menggunakan analisis zat kimia dan spektrum gas yang terkandung di dalamnya. Metode ini memang memiliki akurasi tinggi namun relatif mahal dan memerlukan seorang yang ahli dalam mengoperasikannya. Oleh karena itu, perlu diupayakan metode lain melalui pendekatan aroma untuk mengklasifikasikan mutu kakao, sehingga untuk dapat merealisasikan hal tersebut diperlukan sebuah instrumen yang dapat mentransformasikan pola aroma menjadi sinyal-sinyal listrik terukur yang dapat mengklasifikasi mutu kakao yang diinginkan.

Instrumen penangkap aroma yang berkembang pesat beberapa dekade ini dikenal dengan electronic nose (e-nose)[6]. E-nose merupakan salah satu instrumen elektronik yang bekerja meniru hidung manusia untuk mendeteksi dan menganalisis aroma. $e$-nose terdiri dari sistem pendistribusian aroma sample, larik sensor, rangkaian elektronik dan software untuk analisis data. Pada saat ini, implementasi e-nose banyak digunakan pada industri makanan seperti, kopi, wine, beer, dan lainnya.

E-nose yang terdiri atas larik sensor gas kimia tak selektif berfungsi menangkap dan mentransformasikan aroma menjadi sinyal-sinyal listrik atau respon sensor. Sinyal-sinyal listrik yang dihasilkan ini merupakan senyawa-senyawa pembentuk aroma saling tumpang tindih (overlapping) yang ditangkap oleh larik sensor dengan masing-masing kepekaan yang berbedabeda. Kemudian sinyal-sinyal listrik berupa respon sensor ini membentuk pola-pola khusus untuk jenis aroma yang ditangkap. Adapun untuk dapat mengidentifikasi atau mengklasifikasi pola tersebut tidak dapat dilakukan hanya dengan melihat pola yang dihasilkan secara kuantitatif namun diperlukan analisis lebih lanjut dengan menggunakan mesin pengenalan pola.

Secara umum, e-nose yang merupakan instrumen berbasis kemometri (chemometric), dimana perangkat keras berfungsi mentransformasi aroma menjadi respon sensor dan perangkat

IJEIS Vol. 8, No. 1, April 2018: 49-60 
lunak untuk menganalisis respon sensor dengan menggunakan mesin pengenalan pola berbasis statistik multivarian atau jaringan saraf tiruan (JST). Pengembangan perangkat keras $e$-nose telah banyak dilakukan seperti pengembangan protokol menggunakan hidung elektronik untuk membedakan strain E. coli [7], e-nose untuk pemantauan kualitas udara sehari-hari dalam ruangan[8], meningkatkan sensitivitas dan selektivitas sensor gas Metal Oxide dengan mengendalikan polarisasi lapisan sensitif [9], pemantauan pembusukan makanan dengan hidung elektronik: aplikasi potensial untuk rumah pintar [10], deteksi diabetes dengan mengendus sampel urin berdasarkan e-nose genggam[11], dan pengembangan instrumentasi sistem e-nose untuk uji teh hitam lokal. Kemudian untuk pengembangan perangkat lunak beberapa metode banyak dikembangkan seperti SVM, C-SVM, kNN, RBF, GRNN, dan backpropagation [12], [13], [14], [15], [16]. Adapun tujuan dari pengembangan keduanya agar diperoleh akurasi yang baik, respon sensor relatif stabil, sensitif terhadap intensitas aroma yang rendah dan sebagainya. Sedangkan pengembangan perangkat lunak tujuan utamanya adalah agar diperoleh metode yang tepat di dalam mengklasifikasi atau mengidentifikasi sampel aroma.

Banyak metode pengenalan pola telah digunakan untuk mengidentifikasi atau mengklasifikasi aroma seperti prediksi kualitas teh berbasis hidung elektronik dengan metode LVQ, MLP, PNN, dan RBF [17], aplikasi e nose untuk pengenalan bir menggunakan PCA, RBF, dan backpropagation [18], dan identifikasi kualitas teh hijau berbasis e nose menggunakan CA dan backpropagation. Berbagai metode ini diterapkan pada e nose oleh karena itu belum ada metode baku untuk setiap pengukuran sampel sehingga banyak peneliti yang menggunakan berbagai metode untuk pengukuran yang berbeda-beda. Diantara metode pengenalan pola yang cukup akurat dalam melakukan klasifikasi adalah jaringan saraf tiruan backpropagation. Ada beberapa penelitian e nose yang menggunakan metode ini seperti identifikasi kualitas teh hijau berbasis e nose menggunakan CA dan backpropagation dan klasifikasi kopi dan air tercemar menggunakan backpropagation dan fuzzy backpropagation berbasis e nose [19].

Walaupun metode backpropagation cukup akurat di dalam melakukan analisis pengenalan pola, namun masih terdapat kelemahan diantaranya adalah algoritma kecepatan konvergensi yang lambat, umumnya membutuhkan epoch lebih dari 1000 [20]. Kemudian inisialisasi bobot jaringan dilakukan secara acak, pada akhirnya tidak menguntungkan dalam proses training jaringan secara keseluruhan. Demikian pula capaian untuk mendapatkan jaringan yang optimal menjadi lebih sulit karena data tidak linear, ditambah lagi jika terdapat banyak noise dalam pengambilan data sehingga dimungkinkan juga waktu training menjadi lebih lama. Hal ini dapat menyebabkan data sulit menuju kondisi konvergen untuk error minimum yang ditargetkan. Adapun kelemahan lainnya adalah keluaran jaringan yang bernilai 0 dan 1 , dimana jika pola masukan sesuai dengan target bernilai 1 dan bernilai 0 jika tidak sesuai. Pada kenyataannya dengan target tersebut suatu pola dapat masuk ke dalam dua kelas atau lebih, sehingga diperlukan sebuah metode yang dapat mengatasi permasalahan tersebut.

Logika Fuzzy merupakan seuatu logika yang memiliki nilai kekaburan atau kesamaran (fuzzyness) antara benar atau salah. Menurut teori logika fuzzy suatu nilai dapat bernilai benar atau salah secara bersama, dimana bobot kesalahan suatu himpunan fuzzy tersebut tergantung pada bobot keanggotaan yang dimilikinya. Sedangkan derajat keanggotaan logika fuzzy memiliki rentang antara 0 hingga 1 , sehingga fuzzy memiliki kelebihan dapat memodelkan tingkat kekaburan himpunan fuzzy tersebut [21]. Kelebihan ini biasanya digunakan untuk meyempurnakan kelemahan dari jaringan saraf tiruan dengan data yang memiliki tingkat kekaburan tinggi.

Berdasarkan permasalahan di atas maka pada penelitian klasifikasi aroma mutu kakao ini difokuskan pada penggunaan logika fuzzy untuk memodelkan data yang kabur (fuzzy) sebagai solusi mengatasi permasalahan pada jaringan backpropagation yang memiliki keluaran 0 dan 1. Penggabungan kedua metode tersebut dikenal juga dengan fuzzy neural network (FNN) dengan tipe fuzzy backpropagation. 


\section{METODE PENELITIAN}

\subsection{Bahan}

Bahan yang digunakan sebagai sampel dalam penelitian ini berupa kakao biji yang diperoleh dari PTPN 12 Surabaya. Sampel buah kakao petik dari hasil panen ini terdiri dari tiga sampel: mutu I, mutu II, dan mutu III. Adapun sampel yang diukur aromanya oleh e-nose berupa biji kakao berwarna coklat dan memiliki bau harum coklat yang khas.

\section{2 Peralatan}

Peralatan yang digunakan dalam penelitian ini adalah electronic nose model dinamis dengan ruang sampel dan ruang sensor berada terpisah. Aroma yang dipakai dikirim ke ruang sensor menggunakan sistem aliran udara menggunakan udara bersih dari kompresor. E-nose dinamis ini menggunakan sensor gas berbasis MOS (metal oxide semiconductor) dengan ruang sensor berbentuk bola (Dwisudar, 2016). Adapun deret sensor gas yang digunakan adalah dari jenis MQ x, MQ 1xx, TGS 8xx, dan TGS 26xx. Sensor-sensor gas tersebut bersifat tak selektif dan dapat menangkap senyawa-senyawa volatile tak spesifik, bersifat tumpang tindih (overlapping) sehingga e-nose bersifat umum dan dapat digunakan secara luas.

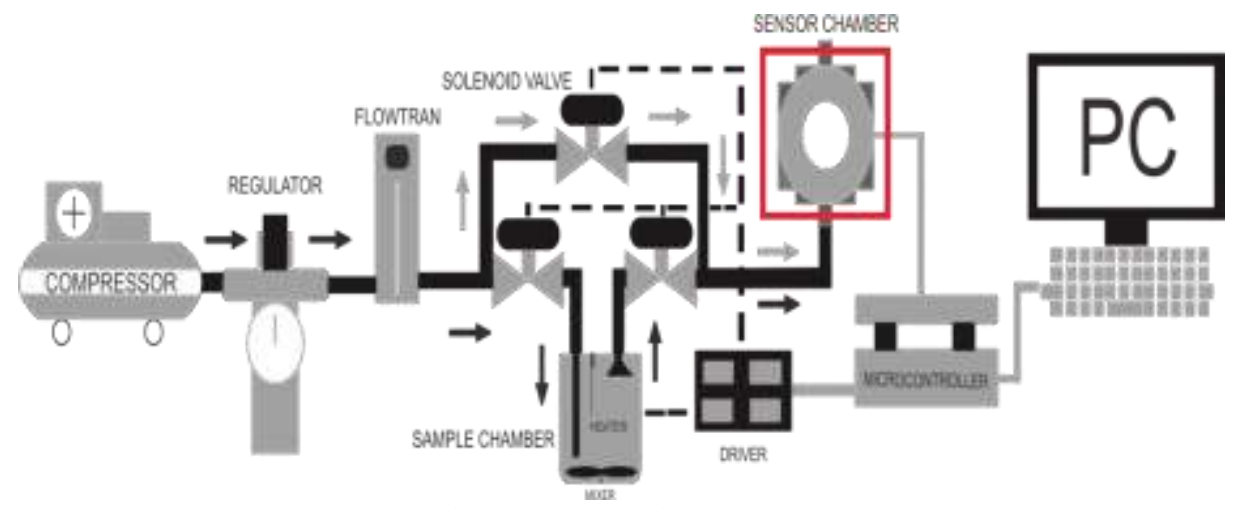

Gambar 1 Diagram blok sistem electronic nose

\section{3 Prosedur dan Pengumpulan Data}

\subsubsection{Preparasi Sampel}

Penelitian ini menggunakan 3 sampel kakao (mutu 1, mutu 2, dan mutu 3). Setiap sampel kakao dibagi menjadi sepuluh buah sampel dengan massa yang sama yaitu 50 gram. Jumlah keseluruhan sampel ada 30 buah. Sampel-sampel ditempatkan dalam wadah plastik untuk menyimpan sampel setelah di timbang. Semua sampel tahu yang total berjumlah 30 buah sampel kemudian diuji dengan electronic nose.

\subsubsection{Pengambilan dan Pengolahan Data}

Penelitian ini bertujuan untuk mengetahui apakah e-nose dapat mengklasifikasi sampel atau tidak. Pengujian dilakukan dengan menggunakan kakao yang diperoleh dari PTPN XII Surabaya. Tahapan-tahapan dalam pengambilan data selama 10 kali tiap sampel dengan rincian flushing 300s, collecting 120s, dan purging 100s. 
Dalam satu kali pengambilan data didapatkan nilai maksimum dan minimum pada setiap puncak dari hasil keluaran sensor, dari nilai tersebut akan digunakan untuk proses ekstraksi ciri. Pada tahap ekstraksi ciri menggunakan metode maksimum, sebelum dilakukan ekstraksi ciri terlabih dahulu melalui proses manipulasi baseline dengan metode diferensial. Penggunaan metode ini dengan menghitung nilai keluaran sensor (data) yang akan diekstrak untuk mendapatkan nilai-nilai yang mempresentasikan ciri spesifik dari data tersebut. Metode differensial disini bertujuan untuk mengurangi penyimpangan (drift) atau derau tambahan (additive noise) pada respon sensor dan mengatasi pergeseran nilai baseline dengan cara menyamakan nilai baseline.

Karena setiap sampel dilakukan 10 kali percobaan maka akan didapatkan sebanyak sepuluh data. Lalu percobaan diulangi sebanyak 10 kali. Data ini akan digunakan sebagai data untuk proses jaringan saraf tiruan fuzzy backpropagation (data pelatihan dan data uji). Jumlah data yang digunakan sebanyak 300 data dari ketiga mutu kakao, dengan 210 data sebagai pelatihan dan 90 data dipergunakan untuk menguji keakuratan sistem yang digunakan untuk mengenali pola masukan. Data latih yang dilatihkan pada fuzzy backpropagation akan menghasilkan bobot. Selanjutnya diuji dengan data uji.

\subsection{Rancangan Topologi}

Jaringan fuzzy backpropagation merupakan jaringan saraf yang mengelompokan data dalam kelas-kelas dengan memperhatikan beberapa parameter seperti fd, fe, epoch, lr, dan hidden layer. Pada Gambar 2, jaringan fuzzy backpropagation memiliki tiga lapisan, yaitu input, hidden layer, dan output. Lapisan input pada jaringan ini dibentuk oleh 12 sensor yaitu MQ 3, MQ 4, MQ 9, MQ 136, TGS 813, TGS 822, TGS 2600, TGS 2602, TGS 2610, TGS 2611, dan TGS 2620. Setiap neuron input terhubung dengan hidden layer dan setiap neuron hidden layer terhubung dengan neuron output. Jumlah neuron pada hidden layer ditentukan dengan trial dan error sehingga diketahui jumlah neuron hidden layer yang optimal. Jumlah neuron output pada lapisan ini sesuai dengan jumlah kelas yang dikehendaki untuk diklasifikasi, karena akan dilakukan klasifikasi pada tiga mutu kakao maka lapisan output pada jaringan ini berjumlah tiga.

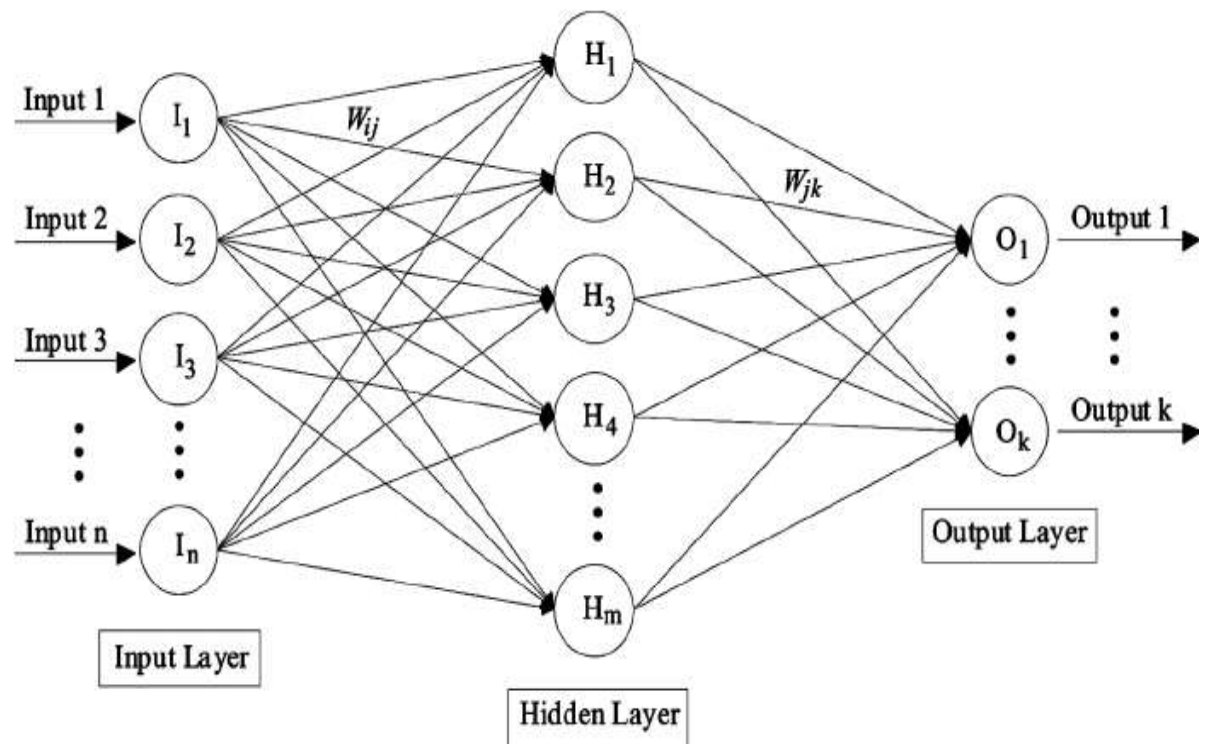

Gambar 2 Rancangan topologi fuzzy backpropagation untuk klasifikasi mutu kakao 


\subsection{Rancangan GUI}

GUI merupakan tampilan program yang dirancang sedemikian rupa sehingga dapat digunakan oleh user dengan mudah. Fungsi dari aplikasi berbasis GUI yang dibuat dengan menggunakan Matlab digunakan untuk mengklasifikasi mutu kakao yang diujikan. Pada aplikasi berbasis GUI ini baik proses training dan proses uji dibuat dalam satu lingkungan (environment).

Program GUI ini dibuat dengan software Matlab. Rancangan GUI ditunjukkan pada Gambar 3

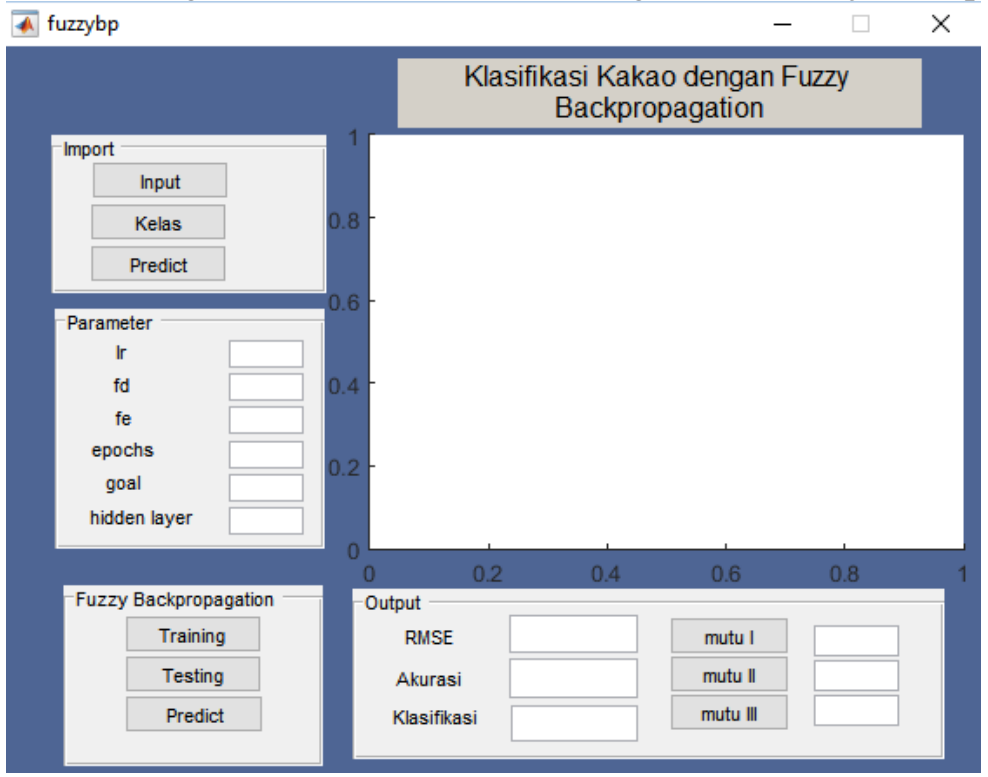

Gambar 3 Rancangan GUI

GUI ini dilengkapi dengan 7 buah tombol push button untuk mengontrol data, 12 buah edit text, serta 1 buah axes. Tombol push button antara lain data training, data kelas, proses training, data testing, proses testing, data prediction, proses prediction. Dua belas buah edit text antara lain parameter yang diatur seperti learning rate (tingkat belajar), fd, fe, epoch (iterasi), goal, hidden layer, RMSE (Root Mean Square Error), akurasi, dan hasil klasifikasi. Satu axes berupa grafik hasil pengujian dengan sumbu x sebagai banyaknya data, dan sumbu y sebagai target yang telah ditentukan.

\section{HASIL DAN PEMBAHASAN}

\subsection{Analisis Hasil Pengambilan Data pada Kakao}

Pada penelitian ini, dirancang dan diimplementasikan sistem untuk mengidentifikasi tahu murni dan tahu berformalin. Untuk membuatnya diperlukan data yang diperoleh dari sinyal yang dihasilkan dari e-nose. Dari sinyal ini didapatkan informasi aspek yang berbeda pada setiap keluaran sensornya. Sinyal yang dihasilkan dari e-nose diperlihatkan pada Gambar 4 


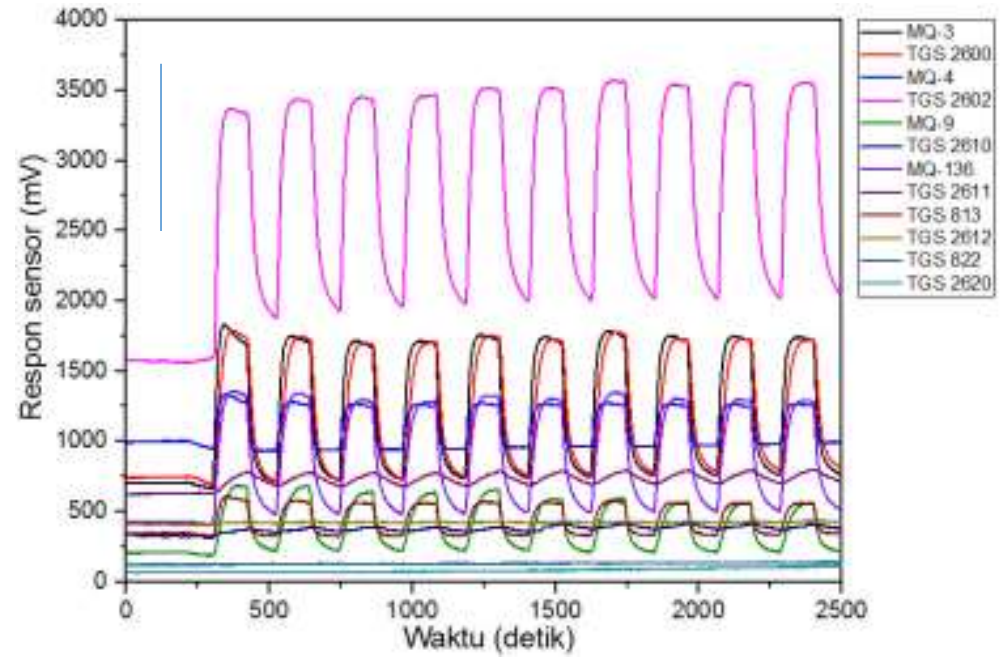

Gambar 4 Grafik respon e-nose terhadap sampel kakao

Respon pada masing-masing sensor terhadap sampel yang diberikan menghasilkan 10 puncak (peak) yang digrafikan dalam bentuk satuan tegangan $(\mathrm{mV})$ terhadap waktu (detik). Selanjutnya data tersebut melalui tahap preprocessing dan ekstraksi ciri dengan menggunakan metode maksimum. Pada tahap ekstraksi ciri dihitung setiap puncak yang telah dihasilkan. Data hasil ekstraksi ciri digunakan untuk melakukan pelatihan program jaringan dan sebagai data latih dan data uji untuk sistem. Sebagai output-nya merupakan kalsifikasi mutu kakao.

\subsection{Preprocessing}

Metode diferensial (differential methode) dilakukan dengan cara mengurangkan respon sinyal dengan baseline-nya. Metode ini mempunyai kelebihan dapat menghilangkan derau (noise) atau penyimpangan (drift) yang muncul pada sinyal sensor. [22]

Gambar 5 merupakan grafik hasil pemrosesan dengan menggunakan metode diferensial. Grafik antara respon sensor (mV) dengan waktu (detik) pada saat proses collecting (120 detik) dengan purging (100 detik) setelah dikurangi dengan nilai baseline- nya. Grafik tersebut skala masing-masing sensor terlihat lebih jelas. Kemudian dari nilai maksimum masing-masing sensor ini memberikan informasi bagi ciri (fingerprint) dari sampel kakao mutu 1.

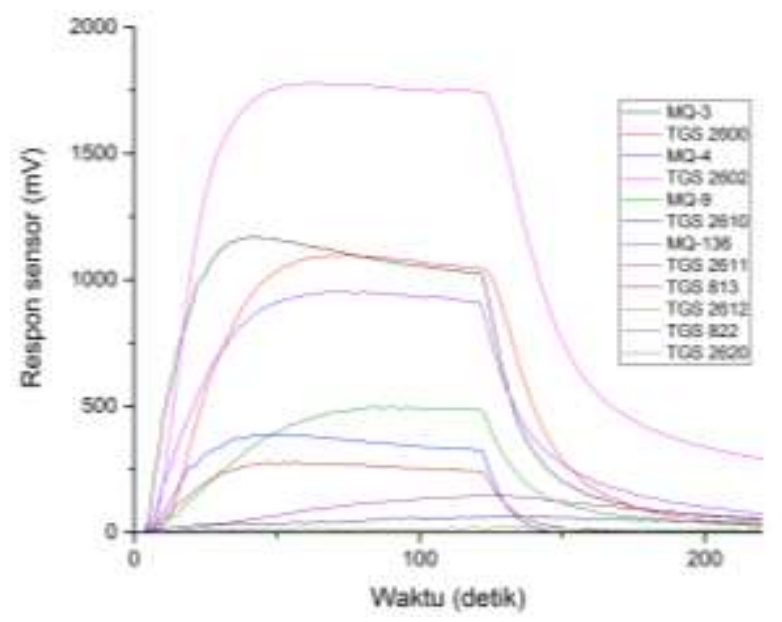

Gambar 5 Hasil dari prapemrosesan menggunakan metode diferensial

\subsection{Ekstraksi Ciri}


Fitur ekstraksi merupakan proses pengambilan informasi yang diperlukan agar dapat diketahui ciri masing-masing respon sensor. Pada penelitian ini sebuah respon sensor terdapat dua belas ciri yang diambil dari dua belas sensor gas yang digunakan. Hasil ekstrasi ciri yang didapat berupa data digital tak terikat oleh waktu. Kemudian data hasil ekstrasi ciri ini ditempatkan ke dalam sebuah matriks besar berordo $300 \times 12$, dimana 300 adalah jumlah data hasil ekstraksi ciri yang berhasil direkam dan 12 kolom merupakan ciri dari sinyal respon sensor yang dapat diambil pada tiap-tiap sensor. Adapun metode pengambilan data pada proses fitur ekstraksi ini dilakukan dengan mengambil nilai maksimum dari masing-masing sinyal sensor sensor yang dihasilkan oleh sensor gas yang digunakan.

\subsection{Pengujian Parameter Pelatihan Fuzzy Backpropagation}

\subsubsection{Pelatihan jaringan dengan variasi fd dan fe}

Tabel 1 Variasi niali fd dan fe pada fuzzy backpropagation

\begin{tabular}{|c|c|c|c|c|c|c|}
\hline No & Fd & Fe & Epoch & MSE & $\begin{array}{c}\text { Akurasi } \\
(\%)\end{array}$ & $\begin{array}{c}\text { Waktu } \\
(\text { menit })\end{array}$ \\
\hline 1 & 1.1 & 1.1 & 10000 & 0.00050534 & 97,75 & $3: 35$ \\
\hline 2 & 1.1 & 2 & 10000 & 0.00025164 & 98,41 & $3: 32$ \\
\hline $\mathbf{3}$ & $\mathbf{1 . 1}$ & $\mathbf{3}$ & $\mathbf{7 4 0 1}$ & $\mathbf{6 . 4 5 E}-\mathbf{0 5}$ & $\mathbf{9 9 , 2 0}$ & $\mathbf{2 : 4 0}$ \\
\hline 4 & 1.1 & 4 & 1981 & 0.00010391 & 98,98 & $0: 53$ \\
\hline 5 & 1.1 & 5 & 10000 & 0.002344 & 95,16 & $4: 54$ \\
\hline
\end{tabular}

Berdasarkan hasil pengujian fd fan fe yang tertera pada Tabel 1, didapatkan nilai epoch sebesar 1767 pada saat nilai $\mathrm{fd}=7 \mathrm{dan} \mathrm{fe}=3$. Untuk menentukan kombinasi $\mathrm{fd}$ dan fe yang optimal maka parameter yang dijadikan acuan adalah nilai MSE. Semakin kecil nilai MSE maka kinerja jaringan semakin baik. Kombinasi fd dan fe terbaik diperoleh ketika nilai fd $=1.1$ dan fe $=3$ dengan nilai MSE 6,45 x $10^{-5}$ dan akurasi 99,20\%.

\subsubsection{Pelatihan jaringan dengan variasi epoch}

Tabel 2 Hasil pelatihan jaringan dengan variasi epoch

\begin{tabular}{|c|c|c|c|c|}
\hline Epoch & $\begin{array}{c}\text { epoch yg } \\
\text { dilakukan }\end{array}$ & akurasi & mse & $\begin{array}{c}\text { Waktu } \\
\text { (menit) }\end{array}$ \\
\hline 10 & 10 & 94 & 0.00403 & $0: 03$ \\
\hline 100 & 62 & 95.1247 & $1.52 \mathrm{E}-03$ & $0: 04$ \\
\hline 1000 & 174 & 99.0009 & $9.00 \mathrm{E}-05$ & $0: 06$ \\
\hline $\mathbf{1 0 0 0 0}$ & $\mathbf{7 4 2}$ & $\mathbf{9 9 . 0 0 4 1}$ & $\mathbf{9 . 9 2 E - 0 5}$ & $\mathbf{0 : 1 7}$ \\
\hline
\end{tabular}

Berdasarkan variasi jumlah epoch tersebut dicari nilai error pelatihan yang mendekati 0 dan akurasi yang mendekati $100 \%$. Dari Tabel 2 terlihat nilai error pelatihan jaringan dengan jumlah epoch yang memiliki error terkecil dan nilai akurasi yang terbesar adalah 10000 epoch. Variasi epoch yang dilakukan pada penelitian ini bertujuan untuk melihat tingkat kekonvergenan setelah melakukan proses iterasi. Konvergen yang dimaksud yaitu dimana semua persamaan akan terseleksikan dan menuju kesuatu nilai yang mendekati dari nilai yang diberikan sehingga jaringan sudah dapat mengenali pola yang diberikan, sehingga dapat dikatakan bahwa jaringan telah siap untuk melakukan tahap pengujian.

\subsubsection{Pelatihan untuk mencari jumlah neuron pada hidden layer}

Tabel 3 Hasil training jaringan dengan variasi neuron pada hidden layer

IJEIS Vol. 8, No. 1, April 2018: 49-60 


\begin{tabular}{|c|c|c|c|c|c|}
\hline Neuron & epoch & $\begin{array}{c}\text { epoch yang } \\
\text { dilakukan }\end{array}$ & Akurasi & Mse & Waktu \\
\hline 10 & 10000 & 950 & 98.6198 & 0.00019 & $0: 21$ \\
\hline 11 & 10000 & 10000 & 98.5624 & 0.000207 & $3: 20$ \\
\hline $\mathbf{1 2}$ & $\mathbf{1 0 0 0 0}$ & $\mathbf{7 7 6}$ & $\mathbf{9 9 . 0 5 1 3}$ & $\mathbf{9 . 0 0 E - 0 5}$ & $\mathbf{0 : 2 6}$ \\
\hline 13 & 10000 & 8908 & 99 & $1.00 \mathrm{E}-04$ & $3: 29$ \\
\hline 14 & 10000 & 243 & 99.0022 & $9.96 \mathrm{E}-05$ & $0: 09$ \\
\hline 15 & 10000 & 787 & 98.2442 & $3.08 \mathrm{E}-04$ & $3: 50$ \\
\hline 16 & 10000 & 2062 & 99.0014 & $9.97 \mathrm{E}-05$ & $0: 56$ \\
\hline 17 & 10000 & 10000 & 97.4663 & $6.42 \mathrm{E}-04$ & $4: 45$ \\
\hline 18 & 10000 & 10000 & 96.3863 & $1.31 \mathrm{E}-03$ & $5: 00$ \\
\hline 19 & 10000 & 10000 & 94.6147 & $2.90 \mathrm{E}-03$ & $5: 25$ \\
\hline 20 & 10000 & 2838 & 99 & $1.00 \mathrm{E}-04$ & $1: 44$ \\
\hline 30 & 10000 & 383 & 99.0055 & $9.89 \mathrm{E}-05$ & $0: 24$ \\
\hline 40 & 10000 & 10000 & 96.9608 & $9.24 \mathrm{E}-04$ & $15: 10$ \\
\hline
\end{tabular}

Pelatihan-pelatihan yang dilakukan dengan cara memvariasi jumlah neuron pada satu lapisan tersembunyi (hidden layer) dan menghasilkan MSE dan epoch yang dibutuhkan ditunjukkan pada Tabel 3. Pada jumlah neuron 10 menghasilkan nilai MSE 0.00019 pada epoch ke-950. Demikian seterusnya untuk nilai-nilai yang lain. Berdasarkan Tabel 3 pula dapat diperlihatkan bahwa hasil pelatihan jaringan dengan memvariasikan jumlah neuron pada hidden

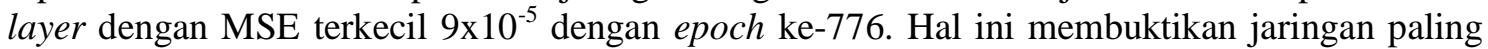
optimal sesuai hasil percobaan dibangun dengan jumlah neuron pada lapisan tersembunyi sebanyak 12. Tetapi hal ini tidak bersifat tetap karena jaringan syaraf tiruan memiliki sifat yang berubah-ubah. Kemudian dari data tersebut dapat dibentuk topologi atau arsitektur jaringan 1212-3, dimana 12 merupakan jumlah neuron masukan (input), 12 adalah jumlah neuron pada lapisan tersembunyi (hidden layer), dan 3 merupakan jumlah neuron keluaran (output).

\subsubsection{Pelatihan untuk Mencari Laju Pembelajaran Terbaik}

Tabel 4 menunjukkan hasil pelatihan jaringan dengan cara memvariasi laju pembelajaran, dimana learning rate 0,001 akan menghasilkan nilai MSE 0,00019 pada epoch ke-10000, demikian seterusnya untuk nilai-nilai yang lainnya.

Tabel 4 Hasil training jaringan dengan variasi laju pembelajaran

\begin{tabular}{|c|c|c|c|c|c|}
\hline $\mathrm{lr}$ & epoch & epoch yang dilakukan & Akurasi & Mse & $\begin{array}{c}\text { Waktu } \\
\text { (menit) }\end{array}$ \\
\hline 0.001 & 10000 & 10000 & 98.6209 & 0.00019 & $3: 43$ \\
\hline 0.01 & 10000 & 133 & 99.0007 & $9.99 \mathrm{E}-05$ & $0: 06$ \\
\hline 0.1 & 10000 & 529 & 99.0016 & $9.97 \mathrm{E}-05$ & $0: 13$ \\
\hline $\mathbf{1}$ & $\mathbf{1 0 0 0 0}$ & $\mathbf{1 4 0 3}$ & $\mathbf{9 9 . 0 0 7 2}$ & $\mathbf{9 . 8 6 E - 0 5}$ & $\mathbf{0 : 3 2}$ \\
\hline
\end{tabular}

\subsection{Hasil Proses Pelatihan (Training)}

Berdasarkan hasil pengujian sebelumnya dengan melakukan variasi parameter-parameter pelatihan, didapat konfigurasi parameter jaringan optimal sebagai berikut.

- $\square$ Arsitektur jaringan : 12-12-3

- $\square$ Jumlah neuron input : 12

- $\square$ Jumlah neuron lapisan tersembunyi : 12 
- $\square$ Jumlah neuron output : 3

- $\square$ Konstanta belajar(learning rate) : 1

- $\square$ Maksimum iterasi (epoch) : 10000

- $\square$ Target error (goal) : 0,0001

\subsection{Hasil Proses Pengujian}

Pengujian dengan fuzzy backpropagation dilakukan dengan menggunakan kombinasi data latih 10\% sampai 90\% dari total data. Hasil pengujian ditunjukkan pada Tabel 5.

Tabel 5 Perbandingan akurasi pengujian berdasarkan persentase data latih

\begin{tabular}{|c|c|c|c|}
\hline No & $\begin{array}{c}\text { Jumlah data } \\
\text { training }\end{array}$ & $\begin{array}{c}\text { Jumlah data } \\
\text { testing }\end{array}$ & $\begin{array}{c}\text { Akurasi } \\
(\%)\end{array}$ \\
\hline 1 & 10 & 90 & 91,5986 \\
\hline 2 & 20 & 80 & 92,45 \\
\hline 3 & 30 & 70 & 92,0307 \\
\hline 4 & 40 & 60 & 92,4249 \\
\hline 5 & 50 & 50 & 92,8075 \\
\hline 6 & 60 & 40 & 92,037 \\
\hline $\mathbf{7}$ & $\mathbf{7 0}$ & $\mathbf{3 0}$ & $\mathbf{9 5 , 2 1}$ \\
\hline 8 & 80 & 20 & 91,49 \\
\hline 9 & 90 & 10 & 88,48 \\
\hline
\end{tabular}

Hasil pengujian terhadap 90 data uji (30\% dari data total) menunjukkan bahwa akurasi program pengujian klasifikasi fuzzy backpropagation sebesar 95,2183\%.

\subsection{Perbandingan Akurasi dengan Backpropagation Konvensional}

Berikut perbandingan akurasi pengujian fuzzy backpropagation dengan backpropagation konvensional sebagaimana dalam tabel 6.

Tabel 6 Perbandingan akurasi fuzzy backpropagation dengan backpropagation konvensional

\begin{tabular}{|c|c|c|c|c|c|}
\hline \multirow{2}{*}{$\begin{array}{c}\text { Persentase } \\
\text { Data Latih }\end{array}$} & \multirow{2}{*}{$\begin{array}{c}\text { Persentase } \\
\text { Data Uji }\end{array}$} & \multirow{2}{*}{$\begin{array}{c}\text { Akurasi Fuzzy } \\
\text { Backpropagation }\end{array}$} & \multicolumn{3}{|c|}{ Akurasi Backpropagation (\%) } \\
\cline { 4 - 6 } & $(\%)$ & $(\%)$ & Target $-1,0,1$ & $\begin{array}{c}\text { Target } \\
1,2,3\end{array}$ & $\begin{array}{c}\text { Target } \\
1,1,1\end{array}$ \\
\hline 70 & 30 & 95,21 & 93,99 & 88,29 & 89,55 \\
\hline
\end{tabular}

Berdasarkan Tabel 6, fuzzy backpropagation terbukti bisa menaikkan akurasi dari backpropagation konvensional dengan kenaikan akurasi 1,22\% dari backpropagation dengan target $(-1,0,1)$, kenaikan $6,92 \%$ dari backpropagation dengan target kelas $(1,2,3)$, dan kenaikan $5,66 \%$ untuk backpropagation dengan target kelas $(1,1,1)$.

\section{KESIMPULAN}

Berdasarkan penelitian yang telah dilakukan maka dapat diambil kesimpulan sebagai berikut

1. Telah berhasil dilakukan klasifikasi mutu kakao dengan electronic nose menggunakan analisa jaringan fuzzy backpropagation.

2. Untuk mengklasifikasi aroma kakao bisa digunakan sensor MQ 3, MQ 4, MQ 9, MQ 136, TGS 813, TGS 822, TGS 2600, TGS 2602, TGS 2610, TGS 2611, dan TGS 2620. 
3. Parameter jaringan yang digunakan yaitu 12 layer pada neuron input, 12 buah neuron pada layer tersembunyi (hidden layer) dan 3 buah neuron pada layer output, nilai learning rate 1.

4. Seluruh sampel kakao (90 data) dapat diklasifikasi dengan baik $(95,21 \%)$ oleh fuzzy backpropagation.

5. Fuzzy Backpropagation dapat menaikkan akurasi klasifikasi backpropagation konvensional.

\section{SARAN}

Saran yang disampaikan penulis untuk pengembangan penelitian yang akan datang adalah sebagai berikut

1. Sistem dapat dikembangkan dengan menghubungkan antara electronic nose dengan perangkat lunak secara langsung, sehingga pengambilan data dan klasifikasi dapat dilakukan dalam waktu yang sama, sehingga proses klasifikasi tidak perlu menggunakan GC (Gas Chromatography).

2. Perlunya penelitian di bidang jaringan syaraf tiruan dengan menggunakan metode lainnya untuk proses klasifikasi, kemudian dilakukan perbandingan sehingga dapat mengetahui metode mana yang efektif untuk melakukan analisa data pada e-nose.

\section{DAFTAR PUSTAKA}

[1] M. E. Prawoto AA, "Pedoman Budi Daya Kakao pada Kebun Campur," Bogor, Indones. World Agrofor. Cent. Southeast Asia Reg. Progr., 2014.

[2] Kemendag, "Rantai Nilai," 2012. [Online]. Available: http://inatrims.kemendag.go.id/id/product/detail/rantai-nilai_1049/?market=ar. [Accessed: 25-Mar-2017].

[3] M. Idris, "Mentan Ingin RI Jadi Produsen Kakao Terbesar Kedua Dunia,” 2016. [Online]. Available: https://finance.detik.com/berita-ekonomi-bisnis/3127133/mentaningin-ri-jadi-produsen-kakao-terbesar-kedua-dunia. [Accessed: 25-Mar-2017].

[4] P. T. Wahyudi, T. R. Panggabean, Panduan Lengkap Kakao. Jakarta: Penebar Swadaya, 2008.

[5] D. Lelono, "Pengembangan Instrumentasi Sistem Electronic Nose untuk Uji Teh Hitam Lokal," Universitas Gadjah Mada, 2017.

[6] S. Baskara, D. Lelono, and T. W. Widodo, "Pengembangan Hidung Elektronik untuk Klasifikasi Mutu Minyak Goreng dengan Metode Principal Component Analysis," IJEIS (Indonesian J. Electron. Instrum. Syst., vol. 6, no. 2, p. 221, 2016.

[7] E. C. Alocija, N. L. Ritchie, and D. L. Grooms, "Protocol development using an electronic nose for differentiating E-coli strains," IEEE Sens. J., vol. 3, no. 6, pp. 801805, 2003.

[8] J. He, L. Xu, P. Wang, and Q. Wang, "A high precise E-nose for daily indoor air quality monitoring in living environment," Integr. VLSI J., no. xxxx, pp. 1-10, 2016.

[9] N. Dufour, Y. Veyrac, P. Menini, F. Blanc, C. Talhi, B. Franc, C. Ganibal, P. Menini, N. Dufour, C. Wartelle, and K. Aguir, "Increasing the sensitivity and selectivity of Metal Oxide gas sensors by controlling the sensitive layer polarization," Proc. IEEE Sensors, no. 2, pp. 3-6, 2012.

[10] G. Green, A. Chan, and R. Goubran, "Monitoring of food spoilage with electronic nose: potential applications for smart homes," 2009 3rd Int. Conf. Pervasive Comput. Technol. Healthc., pp. 1-7, 2009.

[11] T. Seesaard, C. Sriphrapradang, T. Kitiyakara, and T. Kerdcharoen, "Self-screening for diabetes by sniffing urine samples based on a hand-held electronic nose," 2016 9th 
Biomed. Eng. Int. Conf., pp. 1-4, 2016.

[12] C. K. Kit, A. C. Soh, U. Kalsom, M. Yusof, A. J. Ishak, and M. K. Hassan, "E-Nose Herbs Recognition System based on Artificial Neural Network Technique," J. Control Syst. Comput. Eng., pp. 58-62, 2013.

[13] P. F. Qi, Q. H. Meng, Y. Q. Jing, M. Zeng, and S. G. Ma, "Rapid detection of Chinese liquors using a portable e-nose based on C-SVM," Proc. World Congr. Intell. Control Autom., vol. 2016-Septe, pp. 1388-1392, 2016.

[14] C. Engineering and P. Thani, "Classification and pattern recognition algorithms applied to E-Nose," no. Eict, pp. 44-48, 2015.

[15] H. R. Estakhroueiyeh and E. Rashedi, "Detecting moldy Bread using an E-nose and the KNN classifier," 2015 5th Int. Conf. Comput. Knowl. Eng. ICCKE 2015, pp. 251-255, 2015.

[16] H. Yu, J. Wang, C. Yao, H. Zhang, and Y. Yu, "Quality grade identification of green tea using E-nose by CA and ANN," vol. 41, pp. 1268-1273, 2008.

[17] R. Dutta, E. L. Hines, J. W. Gardner, K. R. Kashwan, and M. Bhuyan, "Tea quality prediction using a tin oxide-based electronic nose : an artificial intelligence approach," vol. 94, pp. 228-237, 2003.

[18] M. Siadat and E. Losson, "Application of electronic nose to beer recognition using supervised artificial neural networks," pp. 640-645, 2014.

[19] S. Singh, E. L. Hines, and J. Gardner, "Fuzzy neural computing of coffee and taintedwater data from an electronic nose," Sensors Actuators B Chem., vol. 30, no. 3, pp. 185190, 1996.

[20] X. Yue, Y. Guo, J. Wang, X. Mao, and X. Lei, "Water Pollution Forecasting Model of the Back-Propagation Neural Network Based on One Step Secant Algorithm," vol. 105, 2010, pp. 458-464.

[21] S. Kusumadewi and S. Hartati, Neuro Fuzzy Integrasi Sistem Fuzzy \& Jaringan Syaraf, 2nd ed. Yogyakarta: Graha Ilmu, 2010.

[22] W. Astuti, "Identifikasi Tahu Berformalin dengan Electronic Nose Menggunakan Jaringan Syaraf Tiruan Backpropagation," vol. 6, no. 2, pp. 211-220, 2016. 